\title{
Retroacetabular osteolytic lesions behind well-fixed prosthetic cups: pilot study of bearings-retaining surgery
}

\author{
Luca Pierannunzii · Florian Fischer • \\ Marco d'Imporzano
}

Received: 10 July 2008/Accepted: 12 September 2008/Published online: 25 October 2008

(C) Springer-Verlag 2008

\begin{abstract}
Background Osteolytic lesions are common radiological findings behind acetabular prosthetic cups. If the cup is well-fixed, the management is quite controversial. Although implant exchange is the most reliable procedure, in most cases it could be considered overtreatment, with the potential for further morbidity and bone loss. Liner exchange associated with lesion debridement and grafting represents an alternative option that is less invasive. Here we present our experiences from a small pilot study of minimally invasive osteolysis treatment without bearings exchange in patients with no evidence of liner wear.

Materials and methods Inclusion criteria: retroacetabular osteolytic lesions in ceramic-on-polyethylene or metal-onpolyethylene cementless total hip arthroplasties, affecting more than $50 \%$ of the bone-prosthesis interface on anteroposterior radiography. Exclusion criteria: head penetration into the liner, suspected loosening or infection. Six patients were selected, two asymptomatic and four symptomatic. Only the symptomatic patients accepted the proposed treatment (performed between June 2004 and March 2006). All of them received fluoroscopy-assisted lesion debridement through an iliac cortical window, morcellized bone allograft mixed with autologous platelet-rich plasma, joint exploration for culture and lavage through a small capsular window. Patients were followed up clinically and radiologically at six months, 12 months, and then yearly.
\end{abstract}

L. Pierannunzii · F. Fischer · M. d'Imporzano

III Division of Orthopaedics and Trauma,

Gaetano Pini Orthopaedic Institute,

Piazza C. Ferrari, 1, 20122 Milan, Italy

L. Pierannunzii $(\bowtie)$

Via P. Finzi, 15, 20126 Milan, Italy

e-mail: 1mcpierannunzii@hotmail.com
Results Three patients out of four showed clinical and radiological improvement. One showed radiological improvement only, and recently underwent cup exchange for subsequent loosening. The visual analog scale (VAS) values for pain decreased on average, but not significantly. No major complications occurred. No recurrence was noted at 2.25-4 years' follow-up.

Conclusions Although the small series does not allow any absolute conclusions to be drawn, the reported results seem to justify further, wider studies. It is still unclear if osteolytic lesions associated with no wear of the poly liner would progress to implant failure if left untreated. Until the problem is better understood, this procedure might represent an interesting way to prevent potential loosening and severe bone loss in intact sockets.

Keywords Polyethylene - Wear - Osteolysis · Total hip arthroplasty $\cdot$ Growth factors

\section{Introduction}

Osteolytic lesions are common radiological findings behind acetabular cups in total hip arthroplasties (THA). The frequency with which they are detected is strictly linked to the sensitivity of the imaging technique used in follow-up. Stulber et al. [1] demonstated that CT scan evaluation of hip replacements raises the osteolysis rate to $48 \%$. The causes and developmental mechanisms of osteolytic lesions are still the focus of research, but reaction to debris seems to be the most reasonable explanation by far [2-6]. If this model is correct, periprosthetic osteolysis should be considered a chronic inflammatory response to wear particles. Although polyethylene (PE) is the material that is 
often associated with this granulomatous reaction, ceramics and metal debris are not free from responsibility [7-9].

Particle size plays a major role in determining whether debris phagocytosis will result in a lytic reaction $[10,11]$. Larger particles $(>1 \mu \mathrm{m})$ are more likely to be lined with giant cells, so that the foreign body is virtually removed from the biological environment, while submicron particles can be phagocytosed by macrophages and induce their activation. Activated cells release several proinflammatory cytokines, such as IL-1 and TNF- $\alpha$, whose effects on osteoclastogenesis and osteoclast activity are well known. This effect is probably mediated by resident osteoblasts and stromal cells, which produce RANKL (receptor activator of the NF-kB ligand) in reponse to cytokine stimulation. The interaction between RANKL and its receptor RANK on the surface of hemopoietic precursors and mature osteoclasts may induce both osteoclast precursor differentiation and mature osteoclast activation [12, 13]. Moreover, activated macrophages can take part directly in bone resorption by producing metalloproteinases, which digest the extracellular matrix. The RANKRANKL pathway is inhibited by a soluble competitor of RANKL, osteoprotegerin (OPG), which is secreted by the same cell population (osteoblasts and stromal cells) in response to different stimuli (estradiol, TGF- $\beta 1$, BMP-2, etc.) [14]. The imbalance between local concentrations of RANKL and OPG seems to be a key factor in bone resorption and then in periprosthetic osteolysis [15].

Since wear is an unavoidable phenomenon of any artificial articulation, but gross periprosthetic osteolyses affect only a small number of all THAs, a "wear threshold" can be defined as the wear rate beyond which the biological environment (i.e., periprosthetic bone) is not able to dispose of debris without determining radiologically detectable lytic lesions. $0.1-0.2 \mathrm{~mm} / \mathrm{y}$ are commonly accepted linear wear rate thresholds for polyethylene liners. Osteolysis is not expected to occur below this threshold [16-18]. However, PE wear is not necessarily a steady phenomenon, as bedding-in wear [19] and rim wear by impingement [20] are known to be supplementary mechanisms, and may cause exceptions to the general rule. Thus, the occurrence (and reoccurrence) of osteolysis is more difficult to predict than it would seem from the previous simple model. Lastly, it is not easy to determine when osteolytic lesions will affect cup stability and lead to aseptic loosening, as several factors are involved: extent, location (dome/rim), and involvement of the supportive cortical bone.

Naudie and Engh propose that osteolyses should be treated surgically mainly if they are symptomatic or associated with impending risk of wear-through (i.e., the PE thickness is smaller than $1.5 \mathrm{~mm}$ ). Otherwise, they suggest treating asymptomatic lesions only if they develop early after implantation (i.e., within five years) or they are growing rapidly [21]. The authors substantially agree with the surgical treatment indications provided by Chiang et al. [22] who distinguish between three types of acetabular osteolysis that are eligible for surgery:

- Type I: a well-fixed cup that is modular, properly oriented, intact (especially in relation to the locking mechanism), with favorable track records, and that can accommodate a sufficiently thick insert

- Type II: a well-fixed cup that does not fulfil one of the previous conditions

- Type III: a loose cup

Types II and III deserve standard revision, while type I can be dealt with through liner exchange and local debridement and grafting.

On the other hand, Chang et al. reviewed 62 conventional revisions of well-fixed acetabular components and reported very good results, without severe complications [23]. Thus, they advocate cup revision, especially in young patients, for which surgery should be particularly reliable.

Undoubtedly debridement and grafting are not as effective when performed through the holes of the cup or a cortical window rather than after cup removal [24, 25], and recently Engh et al. [26] demonstrated that the accuracy of the osteolysis grafting procedure is extremely low if the acetabular component is left in situ, as significant parts of the lesion cannot be addressed. However, osteolysis resolution is not clearly related to debridement and grafting, as isolated liner exchange was found to be equally effective in several studies [27-29]. In other words, the removal of the source of debris might allow the spontaneous healing of the untreated lesions.

The purpose of the present pilot study was to test the effectiveness (no recurrence nor subsequent loosening) and the safety (absence of major complications) of the minimally invasive prophylactic treatment of isolated osteolyses without cup or liner exchange in apparently wearless THAs. The rationale of this technique is based on the hypothesis that the release of debris from radiologically intact liners may depend mainly on bedding-in or rim-neck impingement. Since both phenomena may be self-limiting, local treatment of the lesion and joint lavage might be an adequate solution that is able to promote local healing without incurring significant morbidity (infection, dislocation).

\section{Materials and methods}

From June 2004 to March 2006 all of the outpatients with THA followed up at our clinic were evaluated to detect any retroacetabular osteolysis.

Standard plain X-rays were obtained in the anteroposterior and axial views. Head penetration into the polyethylene liner was measured manually by superimposing the 
acetabular cup template onto the anteroposterior film. The technique was shown to be accurate enough for the purposes of our research [30]. Osteolysis detection might have been more sensitive if additional oblique views had been taken [31-33], but the costs and radiation exposures involved were considered excessive, since only gross lesions were selected for treatment.

Retroacetabular osteolytic lesions in ceramic-on-polyethylene or metal-on-polyethylene cementless total hip arthroplasties, affecting more than $50 \%$ of the bone-prosthesis interface on anteroposterior radiography, were considered eligible. The extent of interface involvement was chosen instead of the lesion volume as it was easier to measure and might be more predictive of future loosening. However, no demonstration of such a predictive value was found in the literature.

All of the cases showing head penetration into the liner were excluded, as well as all of those whose clinical or laboratory findings, X-rays or bone scans may have suggested loosening or infection. Symptoms were not considered relevant to selection, unless they clearly suggested loosening or infection.

Six patients were found to satisfy all of the inclusion criteria and none of the exclusion criteria. Four were mildly symptomatic and accepted the proposed treatment, while two were completely pain-free and declined. Descriptive characteristics of the series are displayed in Table 1.
Pain was described as mild and activity-related by all the patients. All of them complained of groin pain, while only patient 1 also complained of buttock pain (Fig. 1). The mean preoperative VAS (visual analog scale) was $36 \mathrm{~mm}$, and the $95 \%$ confidence interval was calculated to lie between 20.91 and 51.09.

All of the lesions underwent fluoroscopy-aided debridement and grafting. The proximal part of a Smith-Petersen approach was performed, the glutei were partly detached from the anterior third of the iliac wing, and the external iliac fossa was exposed [34]. The intermuscular interval was developed distally until the superior part of the neocapsule was recognized. Then, to avoid affecting joint stability, no further dissection was carried out.

A small capsular window was obtained and a sample of periprosthetic fluids was taken for culture. The periprosthetic space was then washed carefully by high-pressure pulsatile lavage, with the aim of reducing the concentration of debris particles. The iliac cortex was drilled under fluoroscopic guidance about $1.5-2 \mathrm{~cm}$ above the dome of the cup. The hole was enlarged until a small curette could be passed through. The lesion was then debrided as completely as possible, and several anteroposterior and oblique views were obtained to check that all of the lesion had been investigated and virtually emptied (Fig. 2).

Morcellized bone allograft was mixed with autologous platelet-rich plasma (PRP) obtained using the GPS System

Table 1 Case series

\begin{tabular}{llllllllll}
\hline Patient no. & Sex & Age & Side & Bearings & $\begin{array}{l}\text { Time from } \\
\text { implantation } \\
\text { (years) }\end{array}$ & $\begin{array}{l}\text { Preoperative } \\
\text { pain (VAS) } \\
\text { (mm) }\end{array}$ & $\begin{array}{l}\text { Postoperative } \\
\text { pain (VAS) } \\
\text { (mm) }\end{array}$ & $\begin{array}{l}\text { Radiological } \\
\text { healing }\end{array}$ & $\begin{array}{l}\text { Follow-up } \\
\text { (years) }\end{array}$ \\
\hline 1 & Male & 68 & Left & Metal-PE & 13 & 39 & 15 & Yes & 4 \\
2 & Male & 54 & Right & Ceramic-PE & 6 & 30 & 16 & Yes & 3.2 \\
3 & Female & 63 & Right & Ceramic-PE & 3 & 27 & 29 & Yes & 3.2 \\
4 & Male & 55 & Right & Ceramic-PE & 5 & 48 & 31 & Yes & 2.25 \\
\hline
\end{tabular}

Fig. 1a-c Patient 1. a Wide retroacetabular osteolysis 13 years after total hip arthroplasty. b one-year postoperative X-ray. c Fouryear postoperative $\mathrm{X}$-ray, showing trabecular incorporation and remodeling
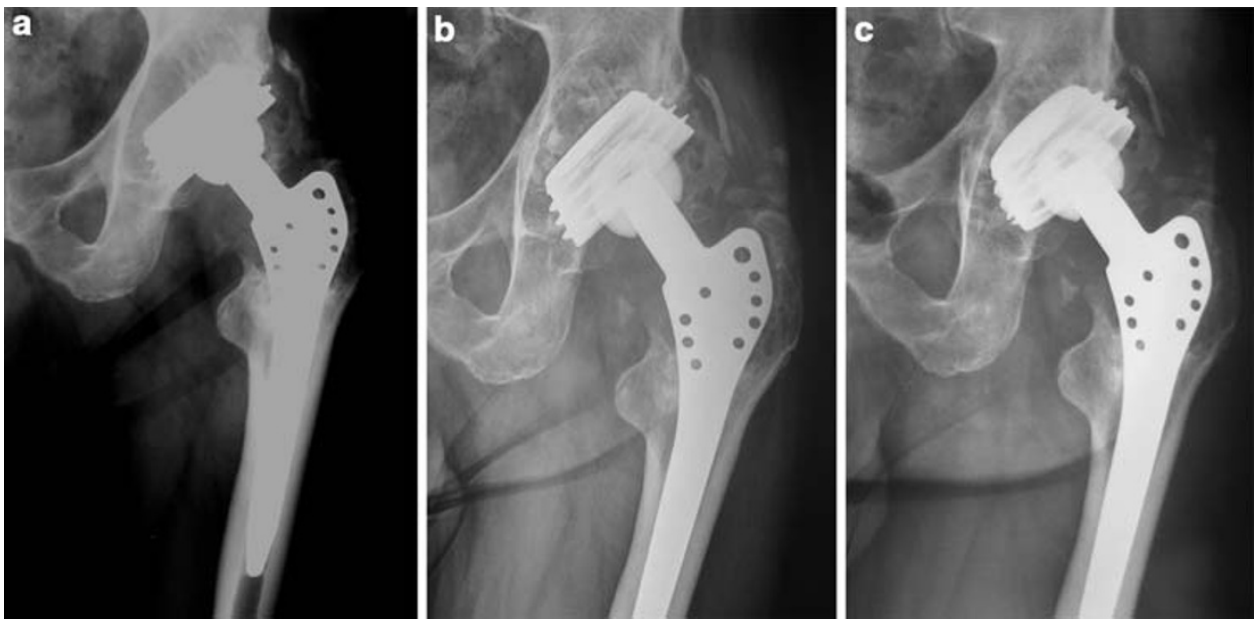


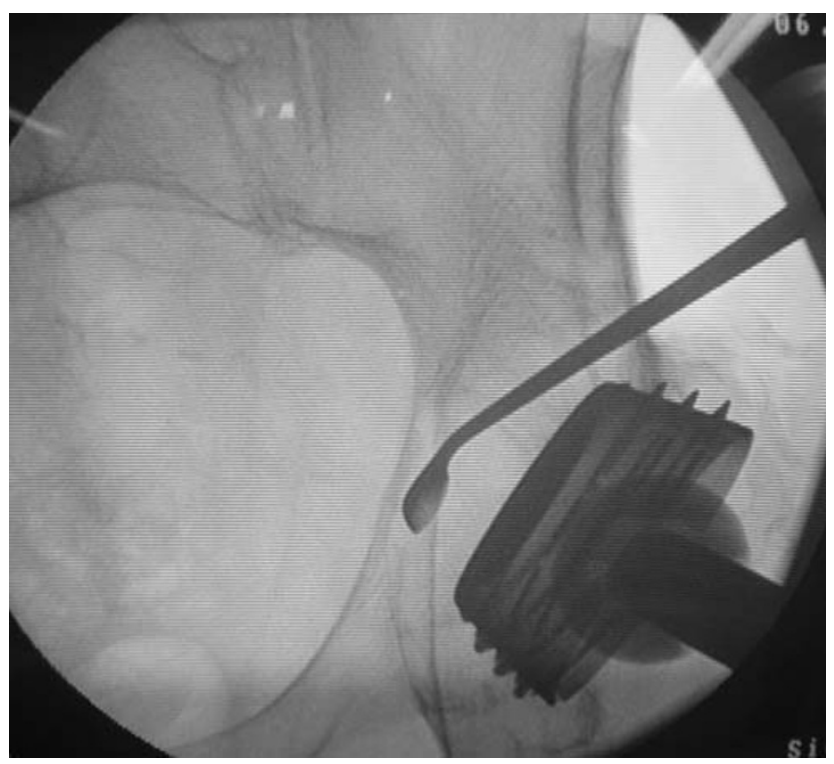

Fig. 2 Curettage under fluoroscopic control

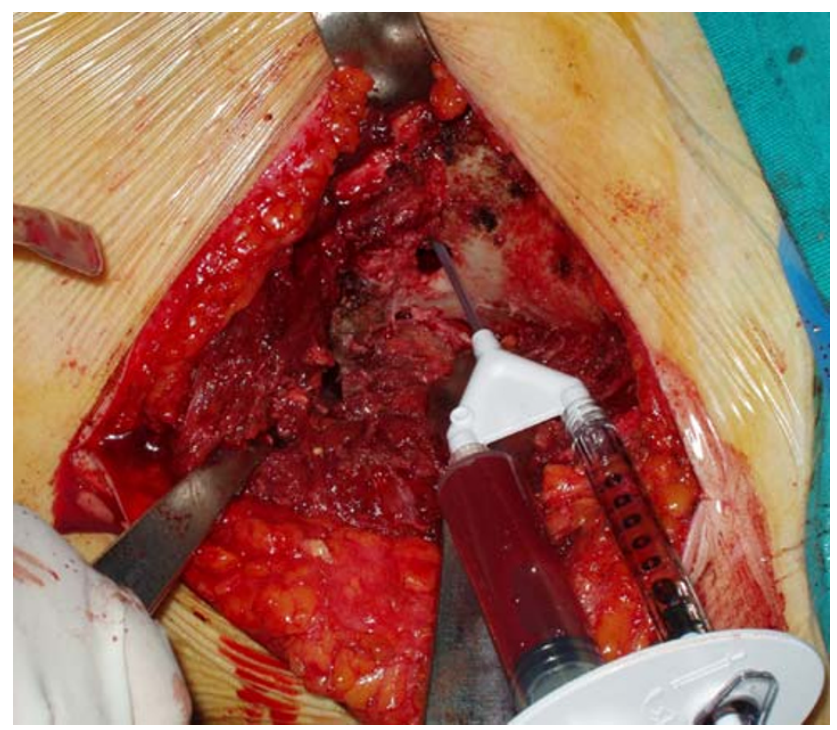

Fig. 3 PRP injection during bone grafting

(Biomet, Warsaw, IN, USA) from a venous blood sample of the patient [35, 36] (Fig. 3). Approximately $10-15 \mathrm{~cm}^{3}$ of the graft was tightly packed inside the cavity until it was filled to the brim of the cortical hole. Lastly, the glutei muscles and the tensor fasciae latae were reattached to the iliac crest via transosseous suture and the wound was closed.

All of the patients received one day of antibiotic prophylaxis with intravenous cefazoline administration $(2 \mathrm{~g}$ before surgery and $1 \mathrm{~g} 6 \mathrm{~h}$ later). Low molecular weight heparins were continued for 30 days after surgery. All of the patients began tolerable weight-bearing from the first postoperative day, and crutches were used for two weeks on average. The four patients were followed up on a regular basis at six months, 12 months, and then yearly. Plain $\mathrm{X}$-rays of the hip were taken and the pain VAS value was recorded at each examination. The radiological images were evaluated according to Linder's stages of impacted graft osseointegration [37]: no change and resorption were interpreted as failures, while trabecular remodellng and incorporation were interpreted as healing. Although the series is extremely undersized, a paired Student's $t$ test was performed to assess the expected reduction in VAS score, and significance was set at 0.05 .

The study protocol was approved by each author. It conforms to the Declaration of Helsinki and was accepted by the Institutional Ethics Committee. All of the patients provided written consent before their enrolment.

\section{Results}

None of the patients developed any major complications (deep venous thrombosis, dislocation, infection). They were discharged to home 3.9 days after surgery on average (range: 3-5). At latest follow up, the mean pain VAS score was 22.8 , with the $95 \%$ confidence interval reaching from 9.35 to 36.15 . Thus, the improvement in symptoms was not statistically significant $(p=0.095)$.

All of the lesions were judged to be radiologically healed, although one patient (patient 3) had developed a growing radiolucent line around the cup at last X-ray (three years after the procedure). The component was considered to be loose and then revised. The surgical findings confirmed the healing of the lesion, and so a pressfit hemispherical cup could be implanted with no need for further bone grafting.

\section{Discussion}

Total hip arthroplasty, as well as any other artificial joint, goes through two working phases: the bedding-in and steady state phases. Bedding-in is characterized by fast radiographical penetration of the head, which is partly due to the head settling into the liner and to the liner settling into the metal back, and partly due to creep. Creep is the plastic deformation that any solid material undergoes when load is applied for a sufficiently long period [38]. In the polyethylene liner, it is intended that creep should increase the contact area, thus lowering the contact pressure. In other words, it improves the frictional performance of the bearing [39]. In the bedding-in phase, head penetration overestimates interface wear by far, as settling-in and deformation are likely to play a major role [40]. However, 
the presence of a smaller contact area during this early phase is likely to result in significantly higher wear than during the following steady phase, in which better congruency is obtained. True bedding-in wear is a difficult-tomeasure phenomenon in THAs with PE liners, because of the important confounding variables listed above, but it is a well-known, easier-to-measure tribological phenomenon in metal-on-metal bearings [41].

The steady state phase occurs six months to two years after implantation, and is characterized by a constant, low speed of head penetration. New crosslinked UHMWPE has a longer bedding-in phase (1-2 years) compared to conventional UHMWPE (six months) [42], and this different viscoelastic behavior may result in greater bedding-in wear. However, the true steady-state linear wear of modern high-quality polyethylene is slightly above the $0.1 \mathrm{~mm} /$ year threshold, while the steady-state wear of crosslinked $\mathrm{PE}$ is so low that it is barely measurable, even with radiostereometric assays [43].

Including the bedding-in penetration, Dorr reported $0.029 \mathrm{~mm} /$ year for Durasul (Sulzer, Austin, TX, US) [44], Engh reported 0.01 for Marathon (DePuy, Warsaw, IN, US) [45], D'Antonio reported 0.055 for Crossfire (Stryker, Mahwah, NJ, US) [46], and Digas reported 0.016 for Longevity (Zimmer, Warsaw, IN, US) [42].

If higher interface wear during the early phase of joint functioning is quite reasonable, higher rim wear looks even more logical. Rim wear is caused by impingement between the prosthetic neck and the rim of the liner. It is likely to occur when prosthetic components are poorly oriented or low-clearance design features (e.g., protruding liners, small head-to-neck ratio) are chosen. Baldini et al. [20] found that $56 \%$ of explanted acetabular cups in THA revision show rim damage. Impingement is now being found to be a relevant factor in THA failure. It initiates at least three different pathomechanisms: it causes loss of material from the edge of the liner (direct effect); it provokes head subluxation and thus increases articular wear; and it has been demonstrated to induce backside wear [47, 48], which has otherwise been almost eliminated in modern acetabular cups [49]. Obviously the direct effect leads to a reduction in the overhanging edge of the liner, which is shaped by impingement through selective wear of the impinging segments. In other words, impingement may be a self-limiting phenomenon, except in the case of severe malpositioning or the wrong choice of prosthetic components.

From what is written above, it follows that PE wear of the articular surface, the rim and the backside is assumed to be higher during the early phase of implant life than the later phase, although no study has actually addressed this problem to the best of our knowledge. This hypothesis was the principle of our bearings-retaining approach: if the wear decreases over time, the recurrence of osteolysis after treatment would be improbable, notwithstanding the retention of the articular components. The choice of including PRP in our management strategy was based on the biology of osteolysis, which seems to be regulated mainly by the positive effect of the RANK-RANKL pathway and by the negative effect of OPG, as described above.

PRP is an effective source of TGF- $\beta 2$, PDGF-AB and IGF-1, growth factors released by activated platelets and capable of a regenerative response that might be useful in local bone healing [50-52]. Specifically, TGF- $\beta 2$ is known to decrease RANKL levels and to increase OPG levels, thus interrupting the main osteolysis pathomechanism [15]. Whether PRP increases the local concentration of bone morphogenetic protein-2 (BMP-2) too is a matter of contention [53, 54]; if this is the case, BMP-2 would be another important stimulus that augments OPG levels [15].

All of these considerations make PRP a potentially useful aid, promoting lesion healing and preventing it from relapse.

One cannot draw definitive conclusions from the results presented here, as the series is too small and the follow-up too short. However, the radiological healing observed in all cases and the absence of recurrence are consistent with the fundamental hypothesis: that most osteolyses that occur without detectable polyethylene wear may be the result of an initial high-wear phase of implant life (perhaps associated with individual hyper-reactivity of the host), after which debris release is insufficient to determine relapse.

Although pain relief is statistically nonsignificant, the inadequate sample size makes statistical significance less reliable. Moreover, such mild discomfort may not be related to osteolysis, the resolution of which seems to be much more important than the disappearance of symptoms.

The strength of the relation between osteolysis and loosening is still unknown: even if patient 3 seems to demonstrate that loosening may develop even with osteolysis healing, one could postulate that occult loosening may have already been occurring at the time of treatment. The surgical importance of healing the lesion was shown in the same case: the restored bone stock allowed a primary cup to be implanted without any further acetabular reconstruction.

Our preliminary results cannot be used to justify the routine management of retroacetabular osteolyses without bearings exchange, but hopefully it may provide the basis for further investigations on larger cohorts.

Conflict of interest statement The authors declare that no benefits nor funds were received in support of this study. 


\section{References}

1. Stulberg SD, Wixson RL, Adams AD, Hendrix RW, Bernfield JB (2002) Monitoring pelvic osteolysis following total hip replacement surgery: an algorithm for surveillance. J Bone Joint Surg 84A(Suppl):116-122

2. Harris WH (2001) Wear and periprosthetic osteolysis: the problem. Clin Orthop 393:66-70

3. Jacobs JJ, Roebuck KA, Archibeck M, Hallab NJ, Glant TT (2001) Osteolysis: basic science. Clin Orthop 393:71-77

4. Sinha RK, Shanbhag AS, Maloney WJ, Hasselman CT, Rubash HE (1998) Osteolysis: cause and effect. Instr Course Lect 47: 307-320

5. Pizzoferrato A, Ciapetti G, Stea S, Toni A (1991) Cellular events in the mechanisms of prosthesis loosening. Clin Mater 7:51-81

6. Santavirta S, Holkka V, Eskola A, Kontinen YT, Paavilainen T, Tallroth K (1990) Aggressive granulomatous lesions in cementless total hip arthroplasty. J Bone Joint Surg Br 72:980-984

7. Hatton A, Nevelos JE, Matthews JB, Fisher J, Ingham E (2003) Effects of clinically relevant alumina ceramic wear particles on TNF-a production by human peripheral blood mononuclear cells. Biomaterials 24:1193-1204

8. Nam KW, Yoo JJ, Kim YL, Kim YM, Lee MH, Kim HJ (2007) Alumina-debris-induced osteolysis in contemporary alumina-onalumina total hip arthroplasty: a case report. J Bone Joint Surg Am 89:2499-2503

9. Jacobs JJ, Hallab NJ (2006) Loosening and osteolysis associated with metal-on-metal bearings: a local effect of metal hypersensitivity? J Bone Joint Surg Am 88:1171-1172

10. Maloney WJ, Smith RL (1996) Periprosthetic osteolysis in total hip arthroplasty: the role of particulate wear debris. Instr Course Lect 45:171-182

11. Maloney WJ, Smith RL, Hvene D, Schmalzried TP, Rubash H (1994) Isolation and characterization of wear debris generated in patients who have had failure of a hip arthroplasty without cement. J Bone Joint Surg Am 77:1301-1310

12. Hsu H, Lacey DL, Dunstan CR et al (1999) Tumor necrosis factor receptor family member RANK mediates osteoclast differentiation and activation induced by osteoprotegerin ligand. Proc Natl Acad Sci USA 96:3540-3545

13. Burgess TL, Qian Y, Kaufman S et al (1999) The ligand for osteoprotegerin (OPGL) directly activates mature osteoclasts. J Cell Biol 145:527-538

14. Yasuda H, Shima N, Nakagawa N, Yamaguchi K, Kinosaki M, Mochizuki SI (1998) Osteoclast differentiation factor is a ligand for osteoprotegerin/osteoclastogenesis-inhibitory factor and is identical to TRANCE/RANKL. Proc Natl Acad Sci USA 95: 3597-3602

15. Holt G, Murnaghan C, Reilly J, Meek RMD (2007) The biology of aseptic osteolysis. Clin Orthop 460:240-252

16. Orishimo KF, Claus AM, Sychterz CJ, Engh CA (2003) Relationship between polyethylene wear and osteolysis in hips with a second generation porous-coated cementless cup after seven years of follow-up. J Bone Joint Surg Am 85:1095-1099

17. Dumbleton JH, Manley MT, Edidin AA (2002) A literature review of the association between wear rate and osteolysis in total hip arthroplasty. J Arthroplasty 17:649-661

18. Sochart DH (1999) Relationship of acetabular wear to osteolysis and loosening in total hip arthroplasty. Clin Orthop 363:135-150

19. Olyslaegers C, Defoort K, Simon JP, Vandenberghe L (2008) Wear in conventional and highly cross-linked polyethylene cups: a 5-year follow-up study. J Arthroplasty 23(4):489-494

20. Shon WY, Baldini T, Peterson MG, Wright TM, Salvati EA (2005) Impingement in total hip arthroplasty: a study of retrieved acetabular components. J Arthroplasty 20(4):427-435
21. Naudie DDR, Engh CA (2004) Surgical management of polyethylene wear and pelvic osteolysis with modular uncemented acetabular components. J Arthroplasty 19(4):124-129

22. Chiang PP, Burke DW, Freiberg AA, Rubash HE (2003) Osteolysis of the pelvis: evaluation and treatment. Clin Orthop 417:164-174

23. Chang JD, Yoo JH, Hur M, Lee SS, Chung YK, Lee CJ (2007) Revision total hip arthroplasty for pelvic osteolysis with wellfixed cementless cup. J Arthroplasty 22(7):987-992

24. Hozack WJ, Mesa JJ, Carey C, Rothman RH (1996) Relationship between polyethylene wear, pelvic osteolysis, and clinical symptomatology in patients with cementless acetabular components: a framework for decision making. J Arthroplasty 11:769772

25. Kavanagh BF, Callaghan JJ, Leggon R, Heekin RD, Wold L (1996) Pelvic osteolysis associated with an uncemented acetabular component in total hip arthroplasty. Orthopedics 19: 159-163

26. Engh CA Jr, Egawa H, Beykirch SE, Hopper RH Jr, Engh CA (2007) The quality of osteolysis grafting with cementless acetabular component retention. Clin Orthop 465:150-154

27. Maloney WJ, Herzwurm P, Paprosky W, Rubash HE, Engh CA (1997) Treatment of pelvic osteolysis associated with a stable acetabular component inserted without cement as part of a total hip replacement. J Bone Joint Surg Am 79:1628-1634

28. Schmalzried TP, Fowble VA, Amstutz HC (1998) The fate of pelvic osteolysis after reoperation: no recurrence with lesional treatment. Clin Orthop 350:128-137

29. Maloney WJ, Paprosky W, Engh CA, Rubash H (2001) Surgical treatment of pelvic osteolysis. Clin Orthop 393:78-84

30. Pollock D, Sychterz CJ, Engh CA (2001) A clinically practical method of manually assessing polyethylene liner thickness. J Bone Joint Surg Am 83:1803-1809

31. Southwell DG, Bechtold JE, Lew WD, Schmidt AH (1999) Improving the detection of acetabular osteolysis using oblique radiographs. J Bone Joint Surg Br 81:289-295

32. Zimlich RH, Fehring TK (2000) Underestimation of pelvic osteolysis: the value of an iliac oblique radiograph. J Arthroplasty 15:796-801

33. Claus AM, Engh CA Jr, Sychterz CJ et al (2003) Radiographic definition of pelvic osteolysis following total hip arthroplasty. J Bone Joint Surg Am 85:1519-1526

34. Smith-Petersen MN (1949) Approach to and exposure of the hip joint for mold arthroplasty. J Bone Joint Surg Am 31:40-46

35. Marx RE, Carlson ER, Eichstaedt RM, Schimmele SR, Strauss JE, Georgeff KR (1998) Platelet-rich plasma: growth factor enhancement for bone grafts. Oral Surg Oral Med Oral Pathol Oral Radiol Endod 85(6):638-646

36. Yazawa $M$, Ogata $H$, Nakajima $T$, Mori $T$, Watanabe $N$, Handa M (2003) Basic studies on the clinical applications of plateletrich plasma. Cell Transplant 12(5):509-518

37. Linder L (2000) Cancellous impaction grafting in the human femur: histological and radiographic observations in 6 autopsy femurs and 8 biopsies. Acta Orthop Scand 71:543-552

38. Glyn-Jones S, McLardy-Smith P, Gill HS, Murray DW (2008) The creep and wear of highly cross-linked polyethylene: a threeyear randomised, controlled trial using radiostereometric analysis. J Bone Joint Surg Br 90(5):556-561

39. Penmetsa JR, Laz PJ, Petrella AJ, Rullkoetter PJ (2006) Influence of polyethylene creep behavior on wear in total hip arthroplasty. J Orthop Res 24(3):422-427

40. Sychterz CJ, Engh A Jr, Yang A, Engh CA (1999) Analysis of temporal wear patterns of porous-coated acetabular components: distinguishing between true wear and so-called bedding-in. J Bone Joint Surg Am 81:821-830 
41. Hu XQ, Isaac GH, Fisher J (2004) Changes in the contact area during the bedding-in wear of different sizes of metal on metal hip prosthesis. Biomed Mater Eng 14(2):145-149

42. Digas G, Kärrholm J, Thanner J, Herberts P (2007) 5-year experience of highly crosslinked polyethylene in cemented and uncemented sockets: two randomized studies using radiostereometric analysis. Acta Orthopaedica 78(6):746-754

43. Bragdon C, Greene M, Freiberg A, Harris W, Malchau H (2007) Radiostereometric analysis comparison of wear of highly cross-linked polyethylene against $36-$ vs $28-\mathrm{mm}$ femoral heads. J Arthroplasty 22(6):125-129

44. Dorr LD, Wan Z, Shahrdar C, Sirianni L, Boutary M, Yun A (2005) Clinical performance of a Durasul highly cross-linked polyethylene acetabular liner for total hip arthroplasty at five years. J Bone Joint Surg Am 87:1816-1821

45. Engh CA Jr, Stepniewski AS, Ginn SD, Beykirch SE, SychterzTerefenko CJ, Hopper RH Jr, Engh CA (2006) A randomized prospective evaluation of outcomes after total hip arthroplasty using cross-linked Marathon and noncross-linked Enduron polyethylene liners. J Arthroplasty 21:17-25

46. D'Antonio JA, Manley MT, Capello WN, Bierbaum BE, Ramakrishnan R, Naughton M, Sutton K (2005) Five-year experience with crossfire highly cross-linked polyethylene. Clin Orthop 441:143-150

47. Usrey MM, Noble PC, Rudner LJ, Conditt MA et al (2006) Does neck/liner impingement increase wear of ultrahigh-molecularweight polyethylene liners? J Arthroplasty 21(6 Suppl 2):65-71
48. Kigman M, Furman BD, Padgett DE, Wright TM (2007) Impingement contributes to backside wear and screw-metallic shell fretting in modular acetabular cups. J Arthroplasty 22(2): 258-264

49. Della Valle AG, Rana A, Furman B, Sculco TP, Salvati EA (2005) Backside wear is low in retrieved modern, modular, and nonmodular acetabular liners. Clin Orthop 440:184-191

50. Weibrich G, Kleis WKG, Hafner G, Hitzler WE (2002) Growth factor levels in platelet-rich plasma and correlations with donor age, sex, and platelet count. J Craniomaxillofac Surg 30(2): 97-102

51. Weibrich G, Buch RS, Kleis WK, Hafner G, Hitzler WE, Wagner W (2002) Quantification of thrombocyte growth factors in platelet concentrates produced by discontinuous cell separation. Growth Factors 20(2):93-97

52. Okuda K, Kawase T, Momose M, Murata M, Saito Y, Suzuki H, Wolff LF, Yoshie H (2003) Platelet-rich plasma contains high levels of platelet-derived growth factor and transforming growth factor-beta and modulates the proliferation of periodontally related cells in vitro. J Periodontol 74(6):849-857

53. Wahlström O, Linder C, Kalén A, Magnusson P (2008) Acidic preparations of platelet concentrates release bone morphogenetic protein-2. Acta Orthop 79(3):433-437

54. Kalén A, Wahlström O, Linder CH, Magnusson P (2008) The content of bone morphogenetic proteins in platelets varies greatly between different platelet donors. Biochem Biophys Res Commun 375(2):261-264 